\title{
Article \\ Accelerated Corneal Endothelial Cell Loss after Phacoemulsification in Patients with Mildly Low Endothelial Cell Density
}

\author{
Hung-Chi Chen ${ }^{1,2,3, *(\mathbb{D})}$, Chen-Wei Huang ${ }^{2}$, Lung-Kun Yeh ${ }^{1,2}{ }^{\text {, Fang-Chi Hsiao }}{ }^{1, *}$, Yi-Jen Hsueh ${ }^{1,3}$, \\ Yaa-Jyuhn James Meir ${ }^{4}$, Kuan-Jen Chen ${ }^{1,2} \mathbb{D}$, Chao-Min Cheng ${ }^{5}$ and Wei-Chi $\mathrm{Wu}^{1,2}$ \\ 1 Department of Ophthalmology, Chang Gung Memorial Hospital, Taoyuan 333423, Taiwan; \\ lkyeh@ms9.hinet.net (L.-K.Y.); t6612@seed.net.tw (Y.-J.H.); cgr999@gmail.com (K.-J.C.); \\ weichi666@gmail.com (W.-C.W.) \\ 2 Department of Medicine, College of Medicine, Chang Gung University, Taoyuan 333323, Taiwan; \\ wayne70521218@gmail.com \\ 3 Center for Tissue Engineering, Chang Gung Memorial Hospital, Taoyuan 333423, Taiwan \\ 4 Department of Biomedical Sciences, College of Medicine, Chang Gung University, Taoyuan 333323, Taiwan; \\ hercats1@gmail.com \\ 5 Institute of Biomedical Engineering, National Tsing Hua University, Hsinchu 300044, Taiwan; \\ chaomin@mx.nthu.edu.tw \\ * Correspondence: mr3756@cgmh.org.tw (H.-C.C.); mtfredh@gmail.com (F.-C.H.); \\ Tel.: +886-3-3281200 (ext. 8666) (H.-C.C. \& F.-C.H.); Fax: +886-3-3287798 (H.-C.C. \& F.-C.H.)
}

check for updates

Citation: Chen, H.-C.; Huang, C.-W.; Yeh, L.-K.; Hsiao, F.-C.; Hsueh, Y.-J.; Meir, Y.-J.J.; Chen, K.-J.; Cheng, C.-M.; Wu, W.-C. Accelerated Corneal Endothelial Cell Loss after Phacoemulsification in Patients with Mildly Low Endothelial Cell Density. J. Clin. Med. 2021, 10, 2270. https:// doi.org/10.3390/jcm10112270

Academic Editor: Marcel Menke

Received: 28 April 2021

Accepted: 20 May 2021

Published: 24 May 2021

Publisher's Note: MDPI stays neutral with regard to jurisdictional claims in published maps and institutional affiliations.

Copyright: (c) 2021 by the authors. Licensee MDPI, Basel, Switzerland. This article is an open access article distributed under the terms and conditions of the Creative Commons Attribution (CC BY) license (https:// creativecommons.org/licenses/by/ $4.0 /)$.
Abstract: By evaluating preoperative endothelial cell density (ECD), ECD loss after phacoemulsification can be predicted. In this retrospective cross-sectional study, we compared outcomes of phacoemulsification with different levels of preoperative ECD. Three-hundred-and-fifty-three patients aged between 18 and 90 years received phacoemulsification at Chang Gung Memorial Hospital. Age $(p=0.003)$, preoperative logMAR $(p=0.048)$, cataract grade $(p=0.005)$, preoperative ECD $(p<0.001)$, operation time $(p=0.043)$, phacoemulsification time $(p=0.001)$, and phacoemulsification energy $(p<0.001)$ were significantly associated with postoperative ECD change $(\%)$. Patients were divided into three groups according to preoperative ECD levels. Level of ECD, coefficient of variation (CV), cell hexagonality (HEX), central corneal thickness (CCT), visual acuity, underlying diseases, and complications were analyzed. With regard to groups, 29, 71, and 252 patients were respectively allocated into the markedly low (group A; ECD below 1000 cells $/ \mathrm{mm}^{2}$ ), mildly low (group B; ECD between 1000 to 2000 cells $/ \mathrm{mm}^{2}$ ), and normal (group C; ECD above 2000 cells $/ \mathrm{mm}^{2}$ ) ECD level groups. The highest CV $(40.8 \pm 13.9 \% ; p<0.001)$ and lowest $\operatorname{HEX}(58.4 \pm 14.6 \% ; p<0.001)$ were found in group A. Significant ECD loss was found in group B $(28.9 \pm 9.2 \%)$ as compared to group A $(19.9 \pm 5.4 \%)$ and $C(15.0 \pm 12.0 \%)(p<0.001)$. No significant differences were found with regard to changes in CV $(p=0.941), \operatorname{HEX}(p=0.937), \operatorname{CCT}(p=0.346)$, and $\log$ MAR $(p=0.557)$ among the three groups. In conclusion, preoperative ECD level could be a novel predictive value for postoperative cell loss, which was the most prominent in mildly low ECD level group. Less phacoemulsification energy, earlier surgical intervention, or novel topical medications could be suggested for patients with an ECD range from 1000 to 2000 cells $/ \mathrm{mm}^{2}$.

Keywords: cataract; phacoemulsification; corneal endothelial cells

\section{Introduction}

Human corneal endothelial cells (HCECs) are responsible for maintaining corneal transparency through regulating the hydration of the corneal stroma. Reduced HCEC, mostly due to previous intraocular surgery, trauma, corneal endotheliitis, and corneal endothelial dystrophy may cause decompensation, leading to corneal edema with visual 
impairment [1-4]. Phacoemulsification for cataracts is one of the most commonly performed surgical procedures, and decreased corneal endothelial cell density (ECD) is a major postoperative complication, resulting in compromised vision $[5,6]$. The known mechanisms include cornea distortion, intraocular lens contact, nuclear fragment contact, free radical production, etc. [3,4,7]. Even with advanced modern techniques, a decline of ECD to approximately $4.2-16.7 \%$ is still inevitable $[3,4,8]$. Thus, identifying the risk factors for increased loss of HCEC is mandatory for optimizing the outcomes of phacoemulsification.

Previously, several preoperative risk factors have been identified to increase ECD loss after phacoemulsification, such as hardness of nucleus, shorter axial length, or presence of diabetes mellitus $[4,9,10]$. Besides, higher consumed ultrasonographic energy, longer aspiration time spent, larger volume of balanced salt solution infused, and posterior capsular rupture during surgery all cause a significant decline in $\operatorname{ECD}[3,4,8,11]$. Although no significant correlation has been detected between preoperative ECD level and postoperative HCEC loss in populations with markedly low ECD levels (ECD $<1000$ cells $/ \mathrm{mm}^{2}$ ) [3,4] and normal ECD levels [11,12] $\left(\mathrm{ECD}>2000\right.$ cells $\left./ \mathrm{mm}^{2}\right)$, little is known about the scenarios in patients with mildly low ECD levels (1000-2000 cells $\left./ \mathrm{mm}^{2}\right)$.

In this study, by comparing three groups of patients with different levels of preoperative corneal ECD, i.e., the markedly low ECD level $\left(<1000\right.$ cells $\left./ \mathrm{mm}^{2}\right)$, mildly low ECD level (1000-2000 cells $\left./ \mathrm{mm}^{2}\right)$, and normal ECD level $\left(>2000\right.$ cells $\left./ \mathrm{mm}^{2}\right)$ groups, we demonstrated significantly more HCEC loss in patients with mildly low ECD than those in the other two groups.

\section{Patients and Methods}

\section{Ethnic Declaration and Participants}

The study was approved and monitored by the Institutional Review Board at Chang Gung Memorial Hospital and adhered to the declaration of Helsinki. A retrospective non-randomized cross-sectional study was conducted by chart review in a 3-year interval. The inclusion criteria of the study group included patients with: (1) history of phacoemulsification with intraocular lens (IOL) implantation due to a cataract; (2) a postoperative follow-up period of more than 3 months; (3) available corneal endothelial examination information both preoperatively and postoperatively; (4) age $>40$ years old. On the other hand, the exclusion criteria included patients with: (1) missing data with regard to specular microscope examination; (2) history of ocular trauma; and (3) previous intraocular surgery.

\section{Surgical Procedure}

The surgical procedures were performed by an experienced surgeon (Chen, $\mathrm{HC}$ ) using standard soft-shell techniques [13-15]. In brief, a side-port and a $2.65 \mathrm{~mm}$ main wound at the temporal side were made at the limbus. Continuous curvilinear capsulorhexis was performed with grasping forceps after viscoelastic substances (Duovisc, Alcon, Fort Worth, TX, USA) were injected into the anterior chamber for space maintenance. The lens nucleus was removed through phacoemulsification using the soft-shell technique, while residual cortex was removed through automated irrigation and aspiration. The phaco device settings for the Infiniti device (Alcon, Fort Worth, TX, USA) were as follows: bottle height, 80 to $100 \mathrm{~cm}$; vacuum pressure, $250 \mathrm{~mm} \mathrm{Hg}$; flow rate, $25 \mathrm{~mL} / \mathrm{min}$; and longitudinal ultrasound power, $50 \%$. A foldable hydrophobic acrylic IOL (AAB00, AMO, Santa Ana, CA, USA) was implanted in the bag with a cartridge and an injector. After complete removal of viscoelastic materials, the clear corneal incisions were hydro-sealed. After surgery, the use of an overnight pressure patch was followed by daily topical betamethasone-tobramycin solution 4 times a day for 1 month.

\section{Ophthalmic Examinations}

All the ophthalmic examinations were performed in both eyes within 1 month preoperatively. Measurements of corneal endothelial morphology and central corneal thickness, accompanied by other routine ophthalmic exams such as visual acuity and intraocular 
pressure were documented for as long as 6 months after surgery. Visual acuity (VA) and best corrected visual acuity (BCVA) were measured by the Snellen chart, with measurements converted to logMAR for analysis. Intraocular pressure (IOP) and biometry including spherical equivalent, corneal curvature, CCT, and axial length were collected via a pneumatonometer (Canon, TX-10, Canon Corporation, Tokyo, Japan), autorefractometer (KR-7000, Tokyo, Japan), and IOLMaster (Carl Zeiss Meditec, Inc., Dublin, CA, USA). We adopted the energy consumed in phacoemulsification to replace cataract grade in this study, which is a numerical but not nominal measure, as recently reported [16]. In addition, a non-contact in vivo specular microscope (CEM-530, Nidek, Gamagori, Japan) with nominal magnification of $400 \times$ was used to take photos of the corneal endothelium for evaluation. The technician measured toward the central cornea once, and extra attempts were made if the image quality could not reach the required threshold. After measurements, data were transmitted to the built-in software program, which immediately calculated the mean cell area, standard deviation, coefficient of variation, ECD, and percentage of hexagonal cells. All the eyes in the study group, the control group, and the contralateral group received identical examinations. If VA and BCVA values were below 0.01 and were recorded as a semiquantitative scale, the value of LogMAR was set at 1.85 for counting fingers, 2.3 for hand motion, 2.6 for light perception, and 2.9 for no light perception according to the experience of Holladay and the University of Freiburg study group results $[17,18]$.

\section{Statistical Analysis}

All of the statistical data were analyzed using SPSS 20 (SPSS Inc. Chicago, IL, USA). The Kolmogorov-Smirnov test was used to check multivariate normality. A $p$-value $<0.05$ was used to define normality. Pearson's chi-squared test was applied to measure the association between ECD changes and age, gender, operation eye, preoperative IOP, preoperative VA, cataract, ocular and systemic cormobilities, preoperative HCEC status, and OP conditions. The impact of variables' on ECD change was evaluated by multiple linear regression analysis. One-way analysis of variance with the Scheffe test was used to evaluate the postoperation parameters, HCEC variance, HCEC hexagonality, ECD loss, and postoperative CCT change among the markedly low ECD group, mild low ECD group, and normal ECD group. A $p$-value $<0.05$ was regarded as a significant difference using a two-tailed probability at $95 \%$ confidence intervals.

\section{Results}

Patients between the ages of 41 and 90 years who received phacoemulsification at Chang Gung Memorial Hospital were included in this retrospective study. During the study period of 2 years, 352 patients with cataract received phacoemulsification with the aforementioned method. To further analyze the postoperative outcomes affected by different preoperative ECD levels, the patients were divided into the markedly low ECD level group (group A; ECD below 1000 cells $/ \mathrm{mm}^{2}$ ), mildly low ECD level group (group B; ECD between 1000 to 2000 cells $/ \mathrm{mm}^{2}$ ), and normal ECD level group (group C; ECD above 2000 cells $/ \mathrm{mm}^{2}$ ), respectively. The Kolmogorov-Smirnov (K-S) test showed that the normal distribution of the preoperative ECD of 352 patients was not present $(p<0.001)$. Nevertheless, the K-S test showed that a normal distribution $(p=0.200, p=0.200)$ was present in groups A and C, but not in group B $(p=0.014)$, suggesting that group B had different characteristics from the other two groups. (Figure S1 and Table S1).

\section{Demographic and Clinical Characteristics of the Preoperative Parameters}

There were 352 cases in this study. The mean age was 69 years, ranging from 41 years to 90 years. Overall, 143 males and 209 females were included. The mean preoperative $\log$ MAR recorded in 352 patients was $1.05 \pm 0.47$. The cataract grade was mostly grade II $(90.9 \%)$. The systemic comorbidities of hypertension and diabetes were present in $133(37.8 \%)$ and 107 (30.4\%) patients. The mean preoperative ECD was $2268.7 \pm 679.5$ cells $/ \mathrm{mm}^{2}$ in the 352 patients. The coefficient of variation and cell hexago- 
nality values were $34.2 \pm 11.1 \%$ and $63.8 \pm 10.0 \%$, respectively. The preoperative mean CCT was $553.3 \pm 34.0 \mu \mathrm{m}$ (Table 1 ).

There were significant differences with regard to preoperative ECD $(p<0.001), \mathrm{CV}$ $(p<0.001), \operatorname{HEX}(p<0.001)$, postoperative ECD $(p<0.001), \mathrm{CV}(p<0.001), \operatorname{HEX}(p=0.001)$, and percentage and number of postoperative ECD changes $(p<0.001)$, as well as Fuchs' endothelial dystrophy $(p<0.001)$. There were no significant differences in age, gender, selected eye, preoperative visual acuity, preoperative intraocular pressure, cataract grade, phacoemulsification energy, anterior chamber depth, ocular and systematic comorbidities including glaucoma, hypertension and diabetes, and preoperative CCT among the groups $\mathrm{A}, \mathrm{B}$, and $\mathrm{C}$ in one-way ANOVA.

The mean ECD in groups A, B, and C appeared significantly different $(p<0.001)$. As for the cell morphology, group $C$ showed a significantly lower coefficient of variation than groups A and B $(p<0.001)$ and significantly higher cell hexagonality than groups A and B $(p<0.001)$. In total, $32(9.1 \%)$ patients had corneal dystrophy, including 29 patients with Fuchs' endothelial dystrophy, 1 with granular dystrophy, and 1 with unspecific corneal dystrophy in group B, and 1 with basement membrane dystrophy in group C (Table 1).

Table 1. Demographic information and ocular status of the 361 patients before phacoemulsification.

\begin{tabular}{|c|c|c|c|c|c|c|}
\hline Parameter & Total & $\begin{array}{c}\text { Chi-Squared Test } \\
p \text { Value }^{+}\end{array}$ & Group A & Group B & Group C & $\begin{array}{c}\text { One-Way ANOVA } \\
p \text { Value }\end{array}$ \\
\hline Participant number & 352 & & 29 & 71 & 252 & \\
\hline \multicolumn{7}{|l|}{ Age (year) } \\
\hline Mean \pm SD & $69.0 \pm 9.9$ & $0.003 *$ & $68.9 \pm 10.0$ & $69.6 \pm 10.1$ & $68.9 \pm 9.9$ & 0.841 \\
\hline Range & $41-90$ & & $48-86$ & $46-87$ & $41-90$ & $\mathrm{~N} / \mathrm{A}$ \\
\hline Gender & & 0.661 & & & & \\
\hline Male & $143(40.6 \%)$ & & $9(31.0 \%)$ & $26(36.6 \%)$ & $108(42.9 \%)$ & 0.352 \\
\hline Female & 209 & & 20 & 45 & 114 & $\mathrm{~N} / \mathrm{A}$ \\
\hline Eye & & 0.416 & & & & \\
\hline Right & $181(51.4 \%)$ & & $17(58.1 \%)$ & $39(54.9 \%)$ & $125(49.6 \%)$ & 0.528 \\
\hline Left & 169 & & 11 & 31 & 127 & $\mathrm{~N} / \mathrm{A}$ \\
\hline Bilateral & 2 & & 1 & 1 & 0 & \\
\hline \multicolumn{7}{|l|}{ Preoperative IOP (mmHg) } \\
\hline Mean \pm SD & $15.0 \pm 4.0$ & 0.365 & $15.4 \pm 4.2$ & $14.6 \pm 3.3$ & $15.0 \pm 4.1$ & 0.570 \\
\hline Preoperative VA & & & & & & \\
\hline Mean $\log M A R \pm S D$ & $1.05 \pm 0.47$ & $0.048^{*}$ & $0.93 \pm 0.33$ & $1.05 \pm 0.45$ & $1.05 \pm 0.49$ & 0.412 \\
\hline Cataract grade $(\%)$ & & $0.005^{*}$ & & & & 0.198 \\
\hline I & $4(1.1 \%)$ & & 0 & $1(1.4 \%)$ & $3(1.2 \%)$ & \\
\hline II & $320(90.9 \%)$ & & $29(100 \%)$ & $61(85.9 \%)$ & $230(91.3 \%)$ & \\
\hline III & $28(8.0 \%)$ & & 0 & $9(12.7 \%)$ & $19(7.5 \%)$ & \\
\hline $\mathrm{ACD}(\mathrm{mm})$ & $2.78 \pm 0.29$ & 0.160 & $2.76 \pm 0.38$ & $2.81 \pm 0.23$ & $2.77 \pm 0.30$ & 0.551 \\
\hline \multicolumn{7}{|l|}{ Comorbidities } \\
\hline Glaucoma & $12(3.4 \%)$ & 0.766 & $0(0 \%)$ & $3(4.2 \%)$ & $9(3.6 \%)$ & 0.555 \\
\hline Corneal dystrophy & $32(9.1 \%)$ & 0.182 & $24(82.1 \%)$ & $4(5.6 \%)$ & $4(1.6 \%)$ & $<0.001 *$ \\
\hline Hypertension & $133(37.8 \%)$ & 0.326 & $11(36.7 \%)$ & $27(38.0 \%)$ & $95(37.7 \%)$ & 0.999 \\
\hline Diabetes mellitus & $107(30.4 \%)$ & 0.923 & $12(40.0 \%)$ & $23(32.4 \%)$ & $72(28.6 \%)$ & 0.338 \\
\hline \multicolumn{7}{|l|}{ Preoperative HCEC status } \\
\hline Cell density $\pm \mathrm{SD}\left(\right.$ cell $\left./ \mathrm{mm}^{2}\right)$ & $2268.7 \pm 679.5$ & $<0.001 *$ & $814.2 \pm 119.7$ & $1512.0 \pm 271.4$ & $2646.1 \pm 288.2$ & $<0.001$ * \\
\hline $\mathrm{CV} \%$ & $34.2 \pm 11.1$ & 0.650 & $40.8 \pm 13.9$ & $36.4 \pm 11.8$ & $32.8 \pm 10.2$ & $<0.001 *$ \\
\hline HEX \% & $63.8 \pm 10.0$ & 0.215 & $58.4 \pm 14.6$ & $60.3 \pm 11.9$ & $65.3 \pm 8.1$ & $<0.001 *$ \\
\hline $\mathrm{CCT}(\mu \mathrm{m})$ Mean $\pm \mathrm{SD}$ & $553.3 \pm 34.0$ & 0.981 & $557.8 \pm 35.7$ & $557.6 \pm 36.1$ & $551.0 \pm 33.7$ & 0.269 \\
\hline
\end{tabular}

Demographic data were collected and analyzed from all patients. ${ }^{*} p$-value $<0.05 .{ }^{+}$The chi-squared test was used to examine the association between factors and postoperative ECD change (\%). ACD: anterior chamber depth; CV: coefficient of variation; CCT: central cornea thickness; IOP: intraocular pressure; HCEC: human corneal endothelial cells; HEX: hexagonality; logMAR: logarithm of the minimum angle of resolution. Group A: Patient preoperative endothelial cell density (ECD) below 1000 cells $/ \mathrm{mm}^{2}$. Group B: Patient preoperative endothelial cell density (ECD) between 1000 and 2000 cells $/ \mathrm{mm}^{2}$. Group C: Patient preoperative endothelial cell density (ECD) above 2000 cells $/ \mathrm{mm}^{2}$.

\section{Intraoperative Parameters and Complications}

The total time spent for operation was $1437.2 \pm 563.1 \mathrm{~s}$ on average in all 352 patients. Mean phacoemulsification time taken and energy consumed in the procedure were $109.7 \pm 77.3 \mathrm{~s}$ and $26.1 \pm 20.0 \mathrm{~mJ}$, respectively. There was no statistical significance in mean operation time, mean phacoemulsification time, and mean phacoemulsification energy between groups A, B, and C (Table 2).

During phacoemulsification, posterior capsular rupture is one of the most commonly seen intraoperative complications. In total, $2(0.6 \%)$ cases of posterior capsular rupture 
were recorded in this study, with one case from group A and the other case from group C (Table 2).

Table 2. Intraoperative features among groups according to preoperative corneal ECD.

\begin{tabular}{|c|c|c|c|c|c|c|}
\hline Parameters & Total & $\begin{array}{c}\text { Chi-Square Test } \\
\quad p \text { Value }^{+}\end{array}$ & Group A & Group B & Group C & $\begin{array}{c}\text { One-Way ANOVA } \\
p \text { Value }\end{array}$ \\
\hline $\begin{array}{l}\text { Participant number } \\
\text { Time spent (s) }\end{array}$ & 352 & & 29 & 71 & 252 & \\
\hline Mean OP time & $1437.2 \pm 563.1$ & $0.043 *$ & $1553.3 \pm 340.3$ & $1417.1 \pm 372.2$ & $1429.5 \pm 624.5$ & 0.505 \\
\hline Mean Phaco time & $109.7 \pm 77.3$ & 0.001 * & $108.9 \pm 43.7$ & $102.6 \pm 62.3$ & $111.9 \pm 83.9$ & 0.697 \\
\hline $\begin{array}{l}\text { Phaco energy }(\mathrm{mJ}) \\
\text { Mean } \pm \text { SD }\end{array}$ & $26.1 \pm 20.0$ & $<0.001$ * & $21.8 \pm 10.1$ & $28.4 \pm 17.4$ & $26.0 \pm 21.5$ & 0.323 \\
\hline PC rupture $(\%)$ & $2(0.6 \%)$ & & $1(3.4 \%)$ & $0(0.0 \%)$ & $1(0.4 \%)$ & \\
\hline
\end{tabular}

${ }^{*} p$-value $<0.05 .{ }^{+}$The chi-squared test was used to examine the association between factors and postoperative ECD change (\%). OP: operation; Phaco: phacoemulsification; PC: posterior capsular. Group A: Patient preoperative endothelial cell density (ECD) below 1000 cells $/ \mathrm{mm}^{2}$. Group B: Patient preoperative endothelial cell density (ECD) between 1000 and 2000 cells $/ \mathrm{mm}^{2}$. Group C: Patient preoperative endothelial cell density (ECD) above 2000 cells $/ \mathrm{mm}^{2}$.

\section{Postoperative Outcomes of HCEC}

The mean postoperative ECD was 1882. \pm 691.8 in the whole 352 patients. The coefficient of variance and cell hexagonality were $37.5 \pm 10.6 \%$ and $59.2 \pm 11.7 \%$, respectively. Combined with the preoperative ECD status, mean HCEC loss was $18.2 \pm 12.3 \%$. As for the cell morphology, the mean coefficient of variance change and mean cell hexagonality change values were $3.3 \pm 11.0 \%$ and $-4.5 \pm 11.1 \%$, respectively, and no statistical significance were observed. Interestingly, mean HCEC loss was $28.9 \pm 9.2 \%$, which was statistically significant higher in group B than in groups A and C (Table 3).

The postoperative CCT change was $9.4 \pm 17.7 \mu \mathrm{m}$, with no statistically significant difference between the three groups. Likewise, the postoperative logMAR change in 1 month was $-0.58 \pm 0.54$, with no statistically significant difference between three groups (Table 3).

Table 3. Corneal and visual outcomes among groups according to preoperative corneal ECD.

\begin{tabular}{|c|c|c|c|c|c|}
\hline Characteristics & Total & Group A & Group B & Group C & $p$ Value \\
\hline Participant number & 352 & 29 & 71 & 252 & \\
\hline \multicolumn{6}{|l|}{ Postoperative HCEC status } \\
\hline Cell density $\pm \mathrm{SD}$ cell $/ \mathrm{mm}^{2}$ & $1882 \pm 691.8$ & $675.4 \pm 112.3$ & $1063.5 \pm 179.2$ & $2251.5 \pm 405.1$ & $<0.001 *$ \\
\hline Cell variance $\pm S D$ & $37.5 \pm 10.6$ & $43.1 \pm 13.1$ & $39.5 \pm 11.5$ & $36.3 \pm 9.7$ & $<0.001 *$ \\
\hline Cell hexagonality $\pm \mathrm{SD}$ & $59.2 \pm 11.7$ & $54.5 \pm 15.3$ & $56.0 \pm 11.9$ & $60.7 \pm 10.9$ & $0.001 *$ \\
\hline $\mathrm{CCT}(\mu \mathrm{m}) \pm \mathrm{SD}$ & $562.7 \pm 33.9$ & $558.8 \pm 35.9$ & $557.6 \pm 36.1$ & $551.5 \pm 33.0$ & 0.133 \\
\hline a $E C D$ change $(\%) \pm S D$ & $-18.2 \pm 12.3$ & $-19.9 \pm 5.4$ & $-28.9 \pm 9.2$ & $-15.0 \pm 12.0$ & $<0.001 *$ \\
\hline${ }^{\mathrm{b}}$ HCEC CV change & $3.3 \pm 11.0$ & $2.7 \pm 13.2$ & $3.1 \pm 11.4$ & $3.4 \pm 10.7$ & 0.941 \\
\hline${ }^{c}$ HCEC hexa. change & $-4.5 \pm 11.1$ & $-3.9 \pm 17.2$ & $-4.4 \pm 10.5$ & $-4.7 \pm 10.5$ & 0.937 \\
\hline \multicolumn{6}{|l|}{ CCT change $(\mu \mathrm{m})$} \\
\hline Mean \pm SD & $9.4 \pm 17.7$ & $13.8 \pm 14.4$ & $8.3 \pm 17.5$ & $9.2 \pm 18.0$ & 0.346 \\
\hline $\begin{array}{l}\text { First month postoperative } \\
\text { logMAR change, Mean } \pm \text { SD (n) }\end{array}$ & $-0.58 \pm 0.54(327)$ & $-0.54 \pm 0.45(28)$ & $-0.52 \pm 0.51(66)$ & $-0.60 \pm 0.56(234)$ & 0.557 \\
\hline
\end{tabular}

${ }^{*} p$-value < 0.05. CCT: central corneal thickness; CV: cell variance; ECD: endothelial cell density; hexa: hexagonality; logMAR: logarithm of the minimum angle of resolution. Group A: Patient preoperative endothelial cell density (ECD) below 1000 cells $/ \mathrm{mm}^{2}$. Group B: Patient preoperative endothelial cell density (ECD) between 1000 and 2000 cells $/ \mathrm{mm}^{2}$. Group C: Patient preoperative endothelial cell density (ECD) above 2000 cells $/ \mathrm{mm}^{2}$. ${ }^{a} \mathrm{ECD}$ change $(\%)=$ (preoperative cell density - postoperative cell density)/preoperative cell density.

${ }^{\mathrm{b}} \mathrm{HCEC} \mathrm{CV}$ change $=$ postoperation $\mathrm{CV}-$ preoperation $\mathrm{CV} .{ }^{\mathrm{c}} \mathrm{HCEC}$ hexa change $=$ postoperation hexa - preoperation hexa.

\section{Factors Associated with HCEC Loss after Phacoemulsification}

Pearson's chi-squared tests evaluated the correlation of postoperative ECD change percentage and factors related to patient's condition and phacoemulsification. There was significant correlation in percentage of ECD change between age $(p=0.003)$, cataract grade $(p=0.005)$, phaco energy $(p<0.001)$, phaco time $(p=0.001)$, total operation time $(p=0.043)$, preoperative $\log$ MAR $(p=0.048)$, and preoperative ECD count $(p<0.001)$ (Tables 1 and 2). A correlation was also shown between age and cataract grade $(p=0.006)$, phaco energy 
$(p<0.001)$, phaco time $(p=0.001)$, gender $(p=0.009)$, hypertension $(p=0.012)$, shallow AC $(p=0.005)$, preoperative IOP $(p=0.025)$, and postphaco HCEC hexa change $(p=0.003)$. A significant correlation was found between phaco energy and age $(p<0.001)$, total OP time $(p<0.001)$, phaco time $(p<0.001)$, cataract grade $(p<0.001)$, postoperative ECD count $(p<0.001)$, and 1-month and 6-month post OP logMAR change $(p=0.009, p=0.010)$. Besides, preoperative CCT was found to be associated with postoperative logMAR change in the first month $(p=0.009)$ but not in the sixth month $(p=0.208)$.

Factors associated with postoperative ECD change were analyzed through multiple linear regression. In the independent variables of age, phaco energy, preoperative logMAR, and preoperative ECD number, the p-values were $0.034,<0.001,0.037$, and $<0.001$ respectively, showing a significant relationship with the dependent variable, percentage of postoperative ECD change (Table 4).

Table 4. Parameters estimated through multiple linear regression analysis.

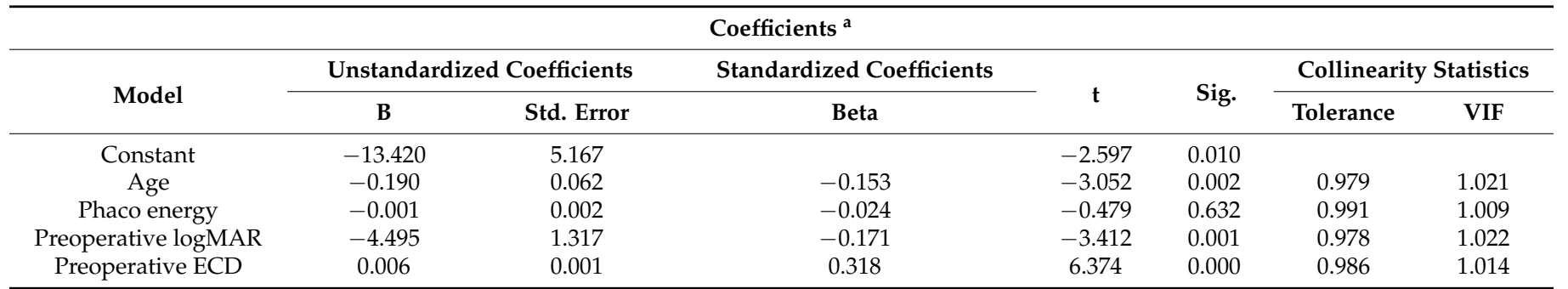

a. Dependent variable: ECD_change (\%). ECD: endothelial cell density; logMAR: logarithm of the minimum angle of resolution; phaco: phacoemulsification.

\section{Discussion}

Previously, higher ECD loss after phacoemulsification was described as being related to age [19], ocular comorbidities such as glaucoma [19], cornea guttata [20], ocular trauma [21], anterior chamber depth [22], eyes with occludable angles [12], cataract grade [23], or the inexperience of surgeons [11] (Table 4). O'Brien et al. reported a similar mean ECD loss rate of $11.6 \%$ in patients operated upon by less experienced surgeons as compared to more senior operators in our study [11]. Ko et al. demonstrated in eyes with occludable angles after phacoemulsification an ECD loss rate as high as $14.5 \%$, and concluded that preoperative IOP, which was not a differential factor in our patients, was associated with the ECD loss rate [12]. Gogate et al. further analyzed different operation methods for ECD loss, and the study included mature cataracts, white cataracts, and up to grade 4 cataracts, which may lead to higher ECD loss rates (18.4\%) [23]. Choi et al. conducted a long-term follow-up of more than 10 years after phacoemulsification and concluded that aging and bullous keratopathy may be responsible for increased ECD loss and compromised visual outcome. Despite the obvious increased ECD loss rate (20.6\%), cell hexagonality and coefficient of variance were found to be similar after the long-term follow up [24]. Notably, all the aforementioned studies focused on patients with normal preoperative ECD levels.

Moreover, some studies excluded patients with mildly or markedly low ECD [11,23-25], while others focused on markedly low ECD [3,4] or had no exclusion criteria for ECD level [12], and showed no significant correlations between preoperative ECD and severity of ECD loss after phacoemulsification. In contrast to previous reports, we further divided our patients into three groups according to preoperative ECD levels and found higher risk for ECD loss in patients with mildly low ECD levels. Interestingly, in our data, preoperative ECD presented a normal distribution in group A and group $C$, but not in group $B$. The normality of ECD number decreased after phacoemulsification in group A and group B, but not in group $C$ due to high skewness in group $C$ (skewness $=-1.16$ ). As for the normality of ECD decrease, a percentage existed only in group A. The ECD was relatively stable in density at $>2000$ cells $/ \mathrm{mm}^{2}$ (group C), and at $<1000$ cells $/ \mathrm{mm}^{2}$ (group A). We assume that the ECD between 1000 and 2000 cells $/ \mathrm{mm}^{2}$ represents a transition status between 
healthy and compromised status; thus, those HCECs are more vulnerable to the damage of phacoemulsification. The ECD distribution after phacoemulsification in this study was in a bimodal mode (Figure S1).

Besides ECD level, coefficient of variance and cell hexagonality were also used to evaluate corneal endothelial function clinically. In normal healthy adults, HCECs present as homogenous hexagonal cells. Once HCECs are lost due to aging, trauma, or other diseases, the remaining cells expand to fill other spaces due to the limited regenerative potential of HCEC. Thus, an increased coefficient of variance and decreased hexagonality would be observed $[26,27]$. The present study showed an increase of $3.3 \%$ with regard to mean of coefficient of variance change and a $4.5 \%$ decrease in hexagonality change in all patients after phacoemulsification. One study reported decreased HCEC hexagonality and increased coefficient of variance 1 month after cataract surgery [28], while another indicated decreased HCEC hexagonality with average endothelial cell size increases immediately after phacoemulsification, but not increased heterogenous HCECs [29]. Our results were consistent with the previous reports. With further analysis, no statistical significance was found for changes in HCEC hexagonality and the coefficient of variance among three groups.

Considering the lower ECD level, lower hexagonality, and higher coefficient of variation, HCECs in the markedly and mildly low ECD level group were indeed in a relatively compromised status compared to those in the normal ECD level group [29]. In general, HCECs would decrease spontaneously with aging regardless of preoperative HCEC status [30]. However, environmental stress, for example through cataract surgery, would accelerate the process of HCEC loss. Accordingly, we advocate preventive strategies such as the use of less phacoemulsification energy and earlier surgical interventions, as well as novel topical corneal endothelial protective agents for patients with mildly low ECD levels [31-33].

The condition of phacoemulsification has been proven to be a crucial intraoperative factor for postoperative ECD loss in previous studies [8,34,35]. Longer phacoemulsification time, higher phacoemulsification energy, high vacuum, and lower phacoemulsification frequency are independent parameters for increasing ECD loss [8,35]. In our results, phacoemulsification time and phacoemulsification energy were recorded and did not show significance statistically significant differences between these three groups, suggesting surgical environments of equal stress. Besides, phacoemulsification time and phacoemulsification energy were usually positively correlated to the density of nucleus, which is also an independent risk factor for ECD loss [8,34]. Our data suggested that phacoemulsification energy was a better risk factor to predict ECD loss after phacoemulsification compared to cataract grade ( $p<0.001$ vs. $p=0.005$ in correlation analysis), similar to the findings pf Tsao et al. [16].

Diabetes mellitus is a common systemic disease worldwide. Except for diabetes retinopathy, major complications of ocular manifestation and other types of corneal dysfunction such as decreased ECD level, decreased HCEC hexagonality, increased coefficient of variance, and increased CCT were also reported [36,37]. In this study, $12(40.0 \%)$ cases of diabetes mellitus were present in the markedly low ECD group, $23(32.4 \%)$ cases in the mildly low ECD group, and $72(28.6 \%)$ cases in the normal ECD group. In a large-scale systematic review, it was shown $1.4 \%$ to $18.4 \%$ non-diabetic and $6.2 \%$ to $29.7 \%$ diabetic patients had complications three months after cataract surgery [38] which is compatible with our results of $18.1 \pm 11.6 \%$.

Posterior capsular rupture is one of the most common complications of cataract surgery, and can lead to postoperative complications such as macular edema, endophthalmitis, or even bullous keratopathy. The prevalence of posterior capsular rupture varies according to different surgeons. Ocular risk factors include hard nucleus, shallow anterior chamber, previous ocular surgery, or concurrent ocular surgery [4,39]. In our results, only two cases in total (one case in group A and one case in group C) were found with posterior 
capsular rupture during the operation. Further follow-up of the two patients failed to detect subsequent postoperative complications.

Only one case of postoperative cornea edema in group $C$ was found. However, we did not record subsequent corneal status indicators such as time to recovery or the need for another corneal transplantation operation. In addition, a reduced focus on postoperative corneal status, subsequent procedure-related complications, and the use other procedures were mentioned in other studies [4,9]. In future work, we will consider postoperative complications and the clinical courses of the patients.

There are several limitations in this study. First, as a retrospective study, not all clinical variances could be precisely determined, and some confounding bias could not be avoided due to different judgment of clinical physicians who recorded the chart. Second, for patients with ocular diseases such as Fuchs' endothelial dystrophy or bullous keratopathy it was difficult to obtain precise ECD levels, which would cause bias. Third, the follow-up period differed from patient to patient depending on the condition and postoperative recovery.

In our study, patients with a preoperative ECD of $2268.7 \pm 679.5$ cells $/ \mathrm{mm}^{2}$ were enrolled. Age, preoperative logMAR, cataract grade, preoperative ECD, operation time, phacoemulsification time, and phacoemulsification energy were significantly associated with postoperative ECD change (\%). Gender, operation eye, hypertension, diabetes, glaucoma, corneal dystrophy, anterior chamber depth, preoperative IOP, CV, HEX, and CCT showed no significant relationships with the postoperative ECD change $(\%)$ change in statistics. We further analyzed the impact of preoperative ECD on postoperative ECD change (\%) and found that the mild low ECD group (ECD between 1000 to 2000 cells $/ \mathrm{mm}^{2}$ ) had a significantly decreased ECD as compared to the normal and low ECD groups, which has been discussed and may be a novel factor to predict ECD change after phacoemulsification. Less phacoemulsification energy, earlier surgical interventions, or novel topical corneal endothelial protective agents might be suggested for patients with ECD ranging from 1000 to 2000 cells $/ \mathrm{mm}^{2}$.

Supplementary Materials: The following are available online at https:/ /www.mdpi.com/article/10 $.3390 / \mathrm{jcm} 10112270 / \mathrm{s} 1$, Figure S1: Histogram of pre- and post-operatively ECD count in this study, Table S1: Normality test of pre- and post-operatively ECD in subgroups.

Author Contributions: Conceptualization, H.-C.C.; Data curation, C.-W.H., L.-K.Y. and Y.-J.H.; Formal analysis, C.-W.H., L.-K.Y., F.-C.H. and Y.-J.J.M.; Funding acquisition, H.-C.C.; Investigation, H.-C.C., Y.-J.H., K.-J.C. and C.-M.C.; Methodology, H.-C.C., F.-C.H., Y.-J.J.M. and C.-M.C.; Project administration, H.-C.C. and W.-C.W.; Supervision, W.-C.W.; Validation, F.-C.H.; Writing-original draft, C.-W.H. and F.-C.H.; Writing-review \& editing, H.-C.C. and F.-C.H. All authors have read and agreed to the published version of the manuscript.

Funding: This study was supported by grants from Chang Gung Memorial Hospital (CMRPG3K1771) and the Ministry of Science and Technology (107-2314-B-182A-088-MY3) to Chen HC.

Institutional Review Board Statement: The study was conducted according to the guidelines of the Declaration of Helsinki, and approved by the Institutional Review Board of Chang Gung Medical Foundation (IRB No.: 201700244B0 and Date of Approval: 6 March 2017).

Informed Consent Statement: Patient consent was waived due to the retrospective design of the study.

Acknowledgments: The authors thank Yen-Ting Chen at Chang Gung Memorial Hospital for his assistance in data supplement.

Conflicts of Interest: The authors have no proprietary or commercial interest in any materials discussed in this article. 


\section{References}

1. Bourne, R.R.A.; Minassian, D.C.; Dart, J.K.G.; Rosen, P.; Kaushal, S.; Wingate, N. Effect of cataract surgery on the corneal endothelium: Modern phacoemulsification compared with extracapsular cataract surgery. Ophthalmology 2004, 111, 679-685. [CrossRef]

2. Traish, A.S.; Colby, K.A. Approaching Cataract Surgery in Patients with Fuchs' Endothelial Dystrophy. Int. Ophthalmol. Clin. 2010, 50, 1-11. [CrossRef] [PubMed]

3. Hayashi, K.; Yoshida, M.; Manabe, S.-I.; Hirata, A. Cataract surgery in eyes with low corneal endothelial cell density. J. Cataract Refract. Surg. 2011, 37, 1419-1425. [CrossRef] [PubMed]

4. Yamazoe, K.; Yamaguchi, T.; Hotta, K.; Satake, Y.; Konomi, K.; Den, S.; Shimazaki, J. Outcomes of cataract surgery in eyes with a low corneal endothelial cell density. J. Cataract Refract. Surg. 2011, 37, 2130-2136. [CrossRef] [PubMed]

5. Mencucci, R.; Ponchietti, C.; Virgili, G.; Giansanti, F.; Menchini, U. Corneal endothelial damage after cataract surgery: Microincision versus standard technique. J. Cataract Refract. Surg. 2006, 32, 1351-1354. [CrossRef]

6. Baradaran-Rafii, A.; Rahmati-Kamel, M.; Eslani, M.; Kiavash, V.; Karimian, F. Effect of hydrodynamic parameters on corneal endothelial cell loss after phacoemulsification. J. Cataract Refract. Surg. 2009, 35, 732-737. [CrossRef]

7. Cameron, M.D.; Poyer, J.F.; Aust, S.D. Identification of free radicals produced during phacoemulsification. J. Cataract Refract. Surg. 2001, 27, 463-470. [CrossRef]

8. Mahdy, M.A.S.; Eid, M.Z.; Mohammed, M.A.-B.; Hafez, A.; Bhatia, J. Relationship between endothelial cell loss and microcoaxial phacoemulsification parameters in noncomplicated cataract surgery. Clin. Ophthalmol. 2012, 6, 503-510. [CrossRef]

9. Hayashi, K.; Hayashi, H.; Nakao, F.; Hayashi, F. Risk factors for corneal endothelial injury during phacoemulsification. J. Cataract Refract. Surg. 1996, 22, 1079-1084. [CrossRef]

10. Walkow, T.; Anders, N.; Klebe, S. Endothelial cell loss after phacoemulsification: Relation to preoperative and intraoperative parameters. J. Cataract Refract. Surg. 2000, 26, 727-732. [CrossRef]

11. O'Brien, P.D.; Fitzpatrick, P.; Kilmartin, D.J.; Beatty, S. Risk factors for endothelial cell loss after phacoemulsification surgery by a junior resident. J. Cataract. Refract. Surg. 2004, 30, 839-843. [CrossRef]

12. Ko, Y.C.; Liu, C.J.; Lau, L.I.; Wu, C.W.; Chou, J.C.; Hsu, W.M. Factors related to corneal endothelial damage after phacoemulsification in eyes with occludable angles. J. Cataract Refract. Surg. 2008, 34, 46-51. [CrossRef]

13. Su, W.-W.; Chen, P.Y.-F.; Hsiao, C.-H.; Chen, H.S.-L. Primary phacoemulsification and intraocular lens implantation for acute primary angle-closure. PLoS ONE 2011, 6, e20056. [CrossRef] [PubMed]

14. Ho, Y.-J.; Sun, C.-C.; Chen, H.-C. Cataract surgery in patients with corneal opacities. BMC Ophthalmol. 2018, 18, 106. [CrossRef] [PubMed]

15. Tarnawska, D.; Wylegała, E. Effectiveness of the soft-shell technique in patients with Fuchs' endothelial dystrophy. J. Cataract Refract. Surg. 2007, 33, 1907-1912. [CrossRef]

16. Tsao, Y.-T.; Wu, W.-C.; Chen, K.-J.; Yeh, L.-K.; Hwang, Y.-S.; Hsueh, Y.-J.; Chen, H.-C.; Cheng, C.-M. Analysis of aqueous humor total antioxidant capacity and its correlation with corneal endothelial health. Bioeng. Transl. Med. 2020, 6, e10199. [CrossRef]

17. Schulze-Bonsel, K.; Feltgen, N.; Burau, H.; Hansen, L.; Bach, M. Visual acuities "hand motion" and "counting fingers" can be quantified with the freiburg visual acuity test. Investig. Ophthalmol. Vis. Sci. 2006, 47, 1236-1240. [CrossRef]

18. Holladay, J.T. Proper method for calculating average visual acuity. J. Refract. Surg. 1997, 13, 388-391. [CrossRef]

19. Ianchulev, T.; Lane, S.; Masis, M.; Lass, J.H.; Benetz, B.A.; Menegay, H.J.; Price, F.W.; Lin, S. Corneal Endothelial Cell Density and Morphology After Phacoemulsification in Patients with Primary Open-Angle Glaucoma and Cataracts: 2-Year Results of a Randomized Multicenter Trial. Cornea 2019, 38, 325-331. [CrossRef]

20. Giasson, C.J.; Solomon, L.D.; Polse, K.A. Morphometry of corneal endothelium in patients with corneal guttata. Ophthalmology 2007, 114, 1469-1475. [CrossRef]

21. Ho, J.W.; Afshari, N.A. Advances in cataract surgery: Preserving the corneal endothelium. Curr. Opin. Ophthalmol. 2015, 26, 22-27. [CrossRef] [PubMed]

22. Hwang, H.B.; Lyu, B.; Yim, H.B.; Lee, N.Y. Endothelial Cell Loss after Phacoemulsification according to Different Anterior Chamber Depths. J. Ophthalmol. 2015, 2015, 210716. [CrossRef] [PubMed]

23. Gogate, P.; Ambardekar, P.; Kulkarni, S.; Deshpande, R.; Joshi, S.; Deshpande, M. Comparison of endothelial cell loss after cataract surgery: Phacoemulsification versus manual small-incision cataract surgery: Six-week results of a randomized control trial. J. Cataract Refract. Surg. 2010, 36, 247-253. [CrossRef]

24. Choi, J.Y.; Han, Y.K. Long-term ( $\geq 10$ years) results of corneal endothelial cell loss after cataract surgery. Can. J. Ophthalmol. 2019, 54, 438-444. [CrossRef] [PubMed]

25. Oshika, T.; Bissen-Miyajima, H.; Fujita, Y.; Hayashi, K.; Mano, T.; Miyata, K.; Sugita, T.; Taira, Y. Prospective randomized comparison of DisCoVisc and Healon5 in phacoemulsification and intraocular lens implantation. Eye 2010, 24, $1376-1381$. [CrossRef]

26. Carlson, K.H.; Bourne, W.M.; McLaren, J.W.; Brubaker, R.F. Variations in human corneal endothelial cell morphology and permeability to fluorescein with age. Exp. Eye Res. 1988, 47, 27-41. [CrossRef]

27. Galgauskas, S.; Norvydaitè, D.; Krasauskaitè, D.; Stech, S.; Ašoklis, R.S. Age-related changes in corneal thickness and endothelial characteristics. Clin. Interv. Aging 2013, 8, 1445-1450. [CrossRef] 
28. Schultz, R.O.; Glasser, D.B.; Matsuda, M.; Yee, R.W.; Edelhauser, H.F. Response of the corneal endothelium to cataract surgery. Arch. Ophthalmol. 1986, 104, 1164-1169. [CrossRef]

29. Tsorbatzoglou, A.; Kertész, K.; Módis, L.; Németh, G.; Máth, J.; Berta, A. Corneal endothelial function after phacoemulsification using the fluid-based system compared to conventional ultrasound technique. Eye 2007, 21, 727-732. [CrossRef]

30. Bourne, W.M.; Nelson, L.R.; Hodge, D.O. Central corneal endothelial cell changes over a ten-year period. Investig. Ophthalmol. Vis. Sci. 1997, 38, 779-782.

31. Lee, C.-Y.; Chen, H.-T.; Hsueh, Y.-J.; Chen, H.-C.; Huang, C.-C.; Meir, Y.-J.J.; Cheng, C.-M.; Wu, W.-C. Perioperative topical ascorbic acid for the prevention of phacoemulsification-related corneal endothelial damage: Two case reports and review of literature. World J. Clin. Cases 2019, 7, 642-649. [CrossRef]

32. Hsiao, F.-C.; Chen, H.-T.; Chen, K.-J.; Hsueh, Y.-J.; Meir, Y.-J.J.; Lu, T.-T.; Cheng, C.-M.; Wu, W.-C.; Chen, H.-C. Accelerated corneal endothelial cell loss in two patients with granulomatosis with polyangiitis following phacoemulsification. BMC Ophthalmol. 2020, 20, 480. [CrossRef]

33. Fujimoto, H.; Setoguchi, Y.; Kiryu, J. The ROCK Inhibitor Ripasudil Shows an Endothelial Protective Effect in Patients with Low Corneal Endothelial Cell Density After Cataract Surgery. Transl. Vis. Sci. Technol. 2021, 10, 18. [CrossRef] [PubMed]

34. Lee, K.M.; Kwon, H.G.; Joo, C.K. Microcoaxial cataract surgery outcomes: Comparison of $1.8 \mathrm{~mm}$ system and $2.2 \mathrm{~mm}$ system. J. Cataract Refract. Surg. 2009, 35, 874-880. [CrossRef] [PubMed]

35. Dewan, T.; Malik, P.K.; Kumari, R. Comparison of effective phacoemulsification time and corneal endothelial cell loss using 2 ultrasound frequencies. J. Cataract Refract. Surg. 2019, 45, 1285-1293. [CrossRef]

36. Lee, J.S.; Oum, B.S.; Choi, H.Y.; Lee, J.E.; Cho, B.M. Differences in corneal thickness and corneal endothelium related to duration in Diabetes. Eye 2006, 20, 315-318. [CrossRef]

37. Lutty, G.A. Effects of Diabetes on the Eye. Investig. Ophthalmol. Vis. Sci. 2013, 54, ORSF81-ORSF87. [CrossRef]

38. Tang, Y.; Chen, X.; Zhang, X.; Tang, Q.; Liu, S.; Yao, K. Clinical evaluation of corneal changes after phacoemulsification in diabetic and non-diabetic cataract patients, a systematic review and meta-analysis. Sci. Rep. 2017, 7, 14128. [CrossRef] [PubMed]

39. Levitz, L.; Reich, J.; Hodge, C. Posterior capsular complication rates with femtosecond laser-assisted cataract surgery: A consecutive comparative cohort and literature review. Clin. Ophthalmol. 2018, 12, 1701-1706. [CrossRef] 